\title{
Hazard cascades
}

\author{
Interacting geological processes can cause complex hazard cascades that threaten life and property. Past events \\ are instructive, but physical understanding must be paired with effective communication to minimize the risks \\ posed by these events.
}

n a time before COVID-19, volcanic ash was perhaps the smallest thing to have grounded entire fleets of aircraft. For a week in 2010, ash from the Eyjafjallajökull eruption in Iceland shut down much of Europe's air space, stranded some ten million passengers, and led to global financial losses of approximately US $\$ 5$ billion ${ }^{1}$. It's not surprising, then, that as reports of seismic unrest on the Reykjanes peninsula of Iceland started to circulate, people wanted to know what the likely disruption of an eruption would be. In this issue of Nature Geoscience, Articles by Namiki et al. and Taddeucci et al., which are further discussed in a News \& Views by Liu, look at the eruption of low-viscosity magmas, similar to those on the move in Iceland. These articles join others from across the Nature portfolio in a collection on geological hazards more generally.

What differentiates geological hazards from geological processes is the potential to cause damage to, and loss of, life and property. Globally, it's estimated that more than 600 million people live in areas susceptible to volcanic hazards alone ${ }^{2}$. The number of people at risk from the full range of geological hazards - including phenomena such as earthquakes and landslides - is much greater, and this will continue to rise as populations increase and urban centres expand ${ }^{2,3}$.

Geological hazards rarely occur in isolation. Instead, they interact with each other and with environmental conditions to form complex hazard cascades, which can exacerbate the associated risks. In addition, anthropogenic activity can interact with, and worsen the impacts of, the geological processes. Potential examples of this were some of the tragic and large landslides associated with the 2018 Palu earthquake in Indonesia. In an area not previously identified as at major risk from landslides, irrigation for rice cultivation primed the ground for liquefaction-induced landsliding, despite the gentle slope ${ }^{4,5}$. The death toll of these landslides may have exceeded several thousand, greater than the estimated fatalities of the tsunami that was triggered by the same earthquake ${ }^{6}$.

Landslides are more commonly triggered by earthquakes without any human interaction. Seismic activity, particularly in mountainous regions, is often associated with hundreds if not thousands of destructive landslides. As exemplified by the 2008 Wenchuan earthquake in China, landslides during earthquakes can cause widespread devastation, but the hazard doesn't disappear when the ground stops shaking ${ }^{7}$. The disturbed nature of slopes after an earthquake can result in landslides being set off by rainfall five to ten times weaker than would have been needed prior to the seismic event ${ }^{8}$. This remobilization and reactivation of debris can cause further damage and fatalities in the days, months and years following an initial event ${ }^{7,8}$.

It's not only earthquakes and landslides that can be linked. Explosive volcanic eruptions can smother vegetation and cause the death and decay of tree roots that had previously stabilized slopes. In southern Chile, landslide rates on densely forested hill slopes that have been covered by volcanic ash and pumice can be ten times higher than on similar slopes unaffected by eruptions ${ }^{9}$. Importantly, unlike the violent mudflows that often accompany volcanic eruptions, these root-death-facilitated landslides only seem to occur two to six years after the event, posing a longer-term hazard.

These examples demonstrate the need to understand how geological, but also anthropogenic, processes interact to threaten communities. Geoscientists increasingly recognize the need for interdisciplinary studies in order to understand hazard cascades, but simply understanding the physical mechanisms is insufficient to mitigate the risks they pose. It has been argued ${ }^{3}$ that the 2004 Indian Ocean earthquake and tsunami should have been anticipated given that the possibility of a large earthquake on the Sumatran plate boundary was recognized. The science was known but an understanding of how to communicate this and motivate building resilience to the potential disaster was missing.

Geoscientists need to work together with social scientists, authorities and community stakeholders if assessments of geological hazards are to be translated into meaningful risk reduction ${ }^{10}$. There is always insight to be gained from looking at past events: it's what most geoscientists are trained to do. But the mitigation of geological hazards also requires us to look forwards, to identify at-risk areas, and to effectively prepare our infrastructure and communities.

Published online: 7 April 2021

https://doi.org/10.1038/s41561-021-00738-9

References

1. Ellertsdottir, E. T. Eyjafiallajökull and the 2010 Closure of European Airspace: Crisis Management, Economic Impact, and Tackling Future Risks (Univ. Dublin, 2014); https://go.nature. com/3tGkosn

2. Auker, M. R., Sparks, R. S. J., Siebert, L., Crosweller, H. S. \& Ewert, J. J. Appl. Volcanol. 2, 2 (2013).

3. Huppert, H. E. \& Sparks, R. S. J. Philos. Trans. R. Soc. A 364, 1875-1888 (2006).

4. Bradley, K. et al. Nat. Geosci. 12, 935-939 (2019).

5. Watkinson, I. M. \& Hall, R. Nat. Geosci. 12, 940-945 (2019)

6. Cummins, P. R. Nat. Geosci. 12, 881-882 (2019).

7. Zhang, S., Zhang, L. M. \& Glade, T. Eng. Geol. 175, 58-73 (2014).

8. Fan, X., Scaringi, G., Xu, Q. \& Huang, R. Eos 100, https://doi. org/10.1029/2019EO126791 (2019).

9. Korup, O., Seidemann, J. \& Mohr, C. H. Nat. Geosci. 12, 284-289 (2019).

10. del Marmol, M.-A. et al. in Observing the Volcano World (eds Fearnley, C. J. et al.) 373-394 (Springer, 2017). 